\title{
Additional Links Between Toxoplasmosis and Psychosis
}

\subsection{Survey of the Historical Data}

After summarizing the 800-year history of the rise of cats and madness, this chapter assesses the strength of the correlation between them. It does so by examining various epidemiolocal and genetic aspects of psychosis and asks how well these fit with Toxoplasma gondii as a possible etiological agent.

So what does English history tell us about cats and madness? In 1233 Pope Gregory issued a papal bull officially designating cats as being in league with Satan. Thereafter for almost 400 years, until the end of the Renaissance, cats were used to guard the grain but otherwise held in very low esteem. On Christian holidays they were often tortured or killed, and to keep a cat as a pet would brand the person as possibly being a witch. During these same years, occasional cases of madness were seen, caused by such things as brain infection, brain trauma, and nutritional deficiencies, as had been true for centuries. But until the end of the Renaissance, there were no suggestions that the incidence of madness was increasing.

The social status of cats began to improve in the seventeenth century as pet keeping became more common. Dogs and birds were the most common pets for most people but some aristocrats, clerics, poets, writers, and artists preferred cats. This trend was accentuated in the eighteenth century when leading intellectuals like Samuel Johnson and Horace Walpole kept cats, as did many of the leading poets, some of whom developed psychosis. For the first time, artists occasionally included cats in paintings of people, especially girls and women. The seventeenth century also saw a striking increase in interest in madness among the public. London's Elizabethan and Jacobian theater depicted madness in many plays. Visits to see the mad people in Bethlem Hospital became a staple for tourists to London; despite having less than 30 patients early in the century, it was widely visited and regarded as a human zoo. By 1676 it had become so overcrowded that a new hospital for 120 patients was built. Several other public psychiatric hospitals began opening, and private mad houses, as they were called, proliferated. All of this activity continued increasing in the eighteenth century. In 1742 it was estimated that 19,000 people 
were visiting Bethlem each year, and in 1770 the hospital was closed to visitors altogether because of the problems they were causing. In 1733 George Cheyne published The English Malady claiming that England had more mad people than any other country and that they were increasing rapidly. The book launched a spirited debate which would continue for almost 200 years.

In the nineteenth century, cats came into their own in England as valued pets. Queen Victoria kept cats along with many other pets, and cats continued to be popular among artists, poets and other writers, and among intellectuals in general. In 1871 the first national cat show was held in London, a measure of how far they had come since their association with Satan. The nineteenth century also witnessed a striking increase in the number of people diagnosed as insane and in public interest in this issue. In 1824 there had been just 8 public asylums in England; by 1890 there were 66, and by 1914 there were 97, each holding 10 times more patients than the original asylums. According to the official census counts of insane persons, there was a fivefold increase per population between 1829 and 1915. During the nineteenth century, the issue of rising insanity became a major concern of parliament and of the public in general.

Concern about rising insanity in the nineteenth century was not unique in England. In The Invisible Plague, we documented similar increases in Ireland, Canada, and the United States, and there are references to similar increases also having occurred in France and Germany. However, among these countries England has the best data on the history of cats as well as good records on the rise of insanity [1].

In examining the data in England for the seventeenth, eighteenth, and nineteenth centuries, there does indeed appear to be a correlation between the rise of cats and the rise of madness. Especially impressive is the increase in public interest, as measured by visits to Bethlem Hospital, suggesting that madness was a new phenomenon. Also impressive are the number of cases of psychosis that occurred among the poets and other writers who had pioneered the keeping of cats as pets.

However just because there is a correlation between the rise of cats and the rise of madness in England does not mean that there is necessarily any relationship, other than a statistical one, between the two. Correlation, in short, is not the same as causation. Two items might be correlated because they cause each other. For example, poverty and lack of education are correlated because they cause each other. Similarly, the sale of sunglasses and the sale of ice cream are correlated because they're both caused by the same thing — warm weather. There are also correlations that are purely accidental. In 2018 "Bloomberg News" published several classic examples of such correlations. For instance, from 2005 to 2011, the number of Facebook users was highly correlated with the Greek debt crisis. And from 1991 to 2009, the number of newborn girls named Ava was highly correlated with the US housing crisis [2].

How, then, can you determine when a correlation does indicate causation? Since the historic rise of cats is correlated with the rise of madness, how can one determine whether or not this is causal? The answer is that you must test for the plausibility of the relationship using other information. In this situation some examples of using other information includes the following. What do we know about the 
prevalence of psychosis among groups that do not keep cats as pets? What do we know about the prevalence of psychosis among groups that have very high rates of infection with Toxoplasma gondii? Can infection with T. gondii explain the epidemiological peculiarities of schizophrenia? For example, why are people who develop schizophrenia more likely to have been born in the winter or spring? Why are they twice as likely to have lived in an urban area, compared to a rural area, in childhood? Why are they more likely to live in a colder climate? In Europe, why is the prevalence of schizophrenia so high among some specific groups of immigrants? Schizophrenia and bipolar disorder are widely claimed to be primarily caused by genetics: can Toxoplasma gondii explain that? And, finally, since 40 million Americans are infected with T. gondii and we have approximately 140 million cats in the country, why isn't psychosis more common?

\subsection{Fewer Cats, Less Psychosis?}

In the 1960s Dr. Gordon Wallace studied the prevalence of cats and the prevalence of Toxoplasma gondii on remote islands in the Pacific Ocean. He established that on islands where cats had never existed, the parasite also did not exist. Similarly, on islands that had seen very few cats, the parasite appeared to be rare. This suggests that groups of people who have had little or no contact with cats should have a lower rate of psychosis insofar as T. gondii causes psychosis [3].

Are there any groups of people who have had minimal exposure to cats and on whom a psychosis prevalence survey has been carried out? The 800,000 people living in the highlands of Papua New Guinea in the 1970s met such criteria. They had had no contact with the outside world until after World War II when gold miners and missionaries began visiting. Since there were no indigenous felines in Papua New Guinea, these people had had no exposure to T. gondii.

In 1929 C. G. Seligman, a British anthropologist who had worked in Papua New Guinea, claimed that he had never seen a case of psychosis among individuals living in remote villages but had seen cases among individuals living along the coast among European traders and missionaries, many of whom had brought their cats with them. In the 1960s Dr. Carlton Gajdusek spent many months in the highlands of Papua New Guinea examining all neurologically impaired individuals in his study of kuru, for which he was later awarded a Nobel Prize. He said that in all of his studies there he had never seen a case of schizophrenia. Based on these reports, in 1973, I carried out a 2-month study of psychiatric patients in Papua New Guinea. With the assistance of the country's only psychiatrist, who had been there for 14 years, I reviewed all 1459 psychiatric case records covering the years 1970 to 1973. All cases of psychosis or probable psychosis were tabulated, with the total number being very low by international standards. I then ascertained the district of birth for all psychosis cases, comparing especially those who had been born in the highland districts, covering 800,000 people who had had possible contact with cats for only a few years, to those who had been born in the coastal districts, covering 1 million people who had had possible contact with cats for 50-70 years. For all cases of psychosis, the prevalence rate in individuals from the coastal districts was five 
times higher than the rate for individuals from the highland districts. For cases that met criteria for schizophrenia, the difference was tenfold. Thus in Papua New Guinea in 1973, a longer exposure to the elements of Western civilization, including possible exposure to cats, was a risk factor for developing psychosis [4].

Another group that has had minimal exposure to cats and on whom psychiatric surveys have been carried out is the Hutterites. They are an Anabaptist sect who migrated from Central Europe to the United States and Canada in 1874-1877. They reside communally in self-sufficient rural colonies living simple and austere lives. Traditionally they have kept no pets, considering it frivolous and unnecessary. When I visited two Hutterite colonies in 1994, a few older women living alone were beginning to keep small dogs as pets but not cats.

A detailed psychiatric survey had been carried out on the Hutterites in 1950-1953. At the time they numbered about 35,000. The prevalence rates for schizophrenia and bipolar disorder were very low by international standards, being 0.9 and 0.6 per 1000 population, respectively. A second detailed survey was carried out in 1992-1997 and reported rates of 1.2 per thousand for schizophrenia and 1.5 per thousand for affective psychosis. These rates are very low by international standards and suggest that having minimal exposure to cats results in a low prevalence of psychosis $[5,6]$.

\subsection{More Toxoplasmosis, More Psychosis?}

The fact that fewer cats are associated with less psychosis suggests that more toxoplasmosis might be associated with more psychosis. In fact, the seropositivity rate indicating past infection with Toxoplasma gondii varies widely from country to country. Studies in France and Ethiopia, for example, have reported rates of $80 \%$ or higher among some segments of the population, whereas other countries, such as China until recently, have reported rates of $10 \%$ or less. Most of these very high rates have been reported from countries where eating undercooked or raw meat is considered a delicacy among some people; France and Ethiopia both fall within this category. However neither France nor Ethiopia has an unusually elevated prevalence rate of psychosis according to studies done there. France has an average rate of psychosis by international standards, and in Ethiopia studies have reported belowaverage prevalence rates. Thus this would appear to be a strong argument that Toxoplasma gondii is not causally related to psychosis [7].

However, there is a possible explanation for this discrepancy. The form of the Toxoplasma gondii parasite that infects people when they ingest tissue cysts in undercooked meat is the bradyzoite form. This is quite different from the form of the parasite that infects people when they ingest or inhale oocysts in contaminated water, while playing in the sandbox, or gardening; that is the sporozoite form. Until recently it was not possible to tell whether an infected person had become infected from tissue cysts or oocysts, but newly developed assays now make this possible. Using these assays it is now known that most congenital forms of toxoplasmosis and most of the North American outbreaks have been caused by oocysts, not tissue cysts. As was mentioned in Chap. 2, studies in mice have shown that infections 
caused by oocysts are more severe than those caused by tissue cysts and there are suggestions that this is also true in humans. Thus it is possible, although not proven, that most cases of toxoplasma- associated psychosis are a consequence of oocyst infection. Insofar as this is true, one would not expect to see a correlation between T. gondii seropositivity rates and the prevalence of psychosis when the rates include both oocyst and tissue system infections [8].

\subsection{Seasonality of Birth}

One of the most clearly established aspects of schizophrenia and bipolar disorder is that there is a winter and spring excess of births for individuals who later develop these diseases. This was initially reported in 1929 in a study in Switzerland and 5 years later in the United States. More than 250 studies have since been done on this phenomena. The seasonal excess is a modest but highly significant $5-8 \%$ for the months of December through April in the northern hemisphere although in some countries for specific months it can be much higher. The seasonal excess is greater for schizophrenia than for bipolar disorder; is more pronounced for individuals born in urban areas; and more pronounced in countries farther away from the equator, for example, greater in Northern Europe than in Southern Europe. No adequate explanation has been offered for the seasonal phenomena. It is been shown that there is no seasonal predisposition to pregnancy among the parents, and the seasonal pattern is not more pronounced in families with a history of schizophrenia or bipolar disorder [9].

How might infection with Toxoplasma gondii explain this seasonal birth pattern? It is known that families keep cats indoors more in the winter than during the warmer weather. It is also thought by some researchers that when a cat becomes infected with $T$. gondii and is excreting millions of infective oocysts daily, the oocysts may become aerosolized when the cat feces dries out after about 24 hours. As such, the oocysts may be inhaled by individuals in the vicinity of the feces and cause clinical toxoplasmosis. As mentioned in Chap. 2, our appreciation of aerosolized oocysts as a threat has increased in recent years based on an outbreak at a riding stable in Atlanta and also by our ability to detect oocysts in an outdoor environment where cats have regularly defecated. Thus, just as pregnant women can become infected with toxoplasmosis by changing the cat litter so too might a newborn baby become infected by breathing in the oocysts, especially if the cat litter is in the same room with the newborn. The newborn might then develop toxoplasma brain cysts that could manifest as schizophrenia two decades later $[10,11]$.

\subsection{Urban Living in Childhood}

Another clearly established epidemiological aspect of schizophrenia is the risk of urban living in childhood. More than 20 studies have reported that children who lived in cities during childhood have twice the risk of later developing schizophrenia compared to those who lived in rural areas. The risk is also dose-dependent 
insofar as the more years the child lived in the city, the greater is the risk. Many explanations, including the stress of urban life, have been offered but none proven.

Since many cities have large numbers of feral cats and since cats prefer to deposit their feces in loose soil or sand, this may provide an explanation. Cities are covered with concrete and offer very few places for cats to defecate. Children's play areas on school grounds and in public parks would be attractive to cats. As will be detailed in the next chapter, studies have reported such areas as being highly infested with T. gondii oocysts. For example, a study of public sandboxes in Japan reported that there were estimated to be more than 1 million oocysts per square foot of sand. In rural areas, by contrast, cats have many more options regarding places to defecate so the concentration of oocysts would be less [12].

\subsection{More Psychosis Where It's Colder}

Still another established epidemiological aspect of psychosis is its association with colder climates. Multiple studies in Europe since the 1960s have reported that the incidence and prevalence of psychosis are higher in Northern Europe than it is in Southern Europe. This was most recently demonstrated by a large study of first episode psychosis at 16 sites in 5 European countries. The incidence of first episode nonaffective psychosis, most of whom have schizophrenia, was higher at the London site than at any other of the 16 sites and was 10 times higher than the incidence of the lowest site, which was Santiago in Spain. The incidence in other Northern European cities-Amsterdam and Paris-was also high, but it was not elevated in the Southern European cities of Madrid, Barcelona, Bologna, or Palermo. In general, the incidence rates at the sites in England, France, and the Netherlands were twice as high as those in Spain and Italy, thus confirming many older studies that have reported a higher incidence of schizophrenia in Northern Europe compared to Southern Europe. Although most such studies have been carried out in Europe, the same pattern was observed in the United States a century ago but has never been reexamined $[13,14]$.

One possible explanation for this striking north to south geographical gradient of psychosis is exposure to the Toxoplasma gondii oocysts. As noted above, in colder weather, cats are much more likely to be kept indoors and thus to defecate in cat litter. If the feces of an infected cat is allowed to dry out, the oocysts may become aerosolized, thereby exposing people living in the household to infection.

\subsection{The Immigrant Issue}

Among the most unusual findings in psychosis research in recent years have been reports of very high rates of psychosis among some, but not other, immigrant groups in European countries, especially in the Netherlands and England. Such studies have not been done in the United States. A striking example are studies of Caribbean immigrants to England. This unusual prevalence was first reported in 1965 and has been confirmed in many studies up to the present. A 1988 study, for example, 
reported the schizophrenia rate for Caribbean immigrants to be ten times higher than the rate for native-born English, and the rate for first-generation offspring of the Caribbean immigrants was even higher. Similarly, a recent study reported that "the incidence of all psychoses was over six times higher in African populations in the UK, compared with the British" [15-18].

How might these unusual findings be explained by infection with Toxoplasma gondii? It is known that the rate of exposure to $T$. gondii among people living in the Caribbean region is very high, as measured among pregnant women living there. A review of studies from ten English-speaking Caribbean countries reported that "a sizeable human population in the Caribbean becomes infected with T. gondii during childhood." However, the prevalence of schizophrenia is not unusually high there. Of special interest, however, is the fact that the predominant strains of the T. gondii parasite are different in the Caribbean than in England, and it is known that different strains can produce very different clinical outcomes. Whereas the type II strain is thought to be predominant in England as well as the United States, the type III and many atypical strains are predominant in the Caribbean. Since people can become infected with more than one strain, it may be a combination of strains that causes psychosis. Regarding the children of the Caribbean immigrants who are born in England and are also known to have a high incidence of psychosis, many of these children go back and forth between England and the Caribbean and often "live for some years with relatives at home," thus exposing them to T. gondii and other infectious agents in the Caribbean as well as in England [19-22].

\subsection{Isn't Schizophrenia Genetic?}

Textbooks of psychiatry now claim that schizophrenia and bipolar disorder are primarily genetic diseases. By this is meant that genes play a dominant role in the etiology, which for schizophrenia has been estimated by some geneticists to be $80 \%$ or greater. In fact schizophrenia is not primarily a genetic disease. It is of course a familial disease, meaning that it runs in families, but being familial is not the same as being genetic. Many traits can be familial but not genetic, such as speaking Spanish.

How do we know that schizophrenia is not primarily a genetic disease? One reason is that, despite the expenditure of literally hundreds of millions of dollars over two decades, no evidence has emerged to support schizophrenia as being primarily a genetic disease. As one critic described the research in 2016, "The current trend in psychiatric genetics is to use enormous samples to find genes of minuscule effect." In fact the strongest and most replicated schizophrenia genetic finding to date has been the findings in the MHC complex of chromosome 6 pointing to infectious, inflammatory, or immunologic factors as being of greatest importance $[23,24]$.

We also know that schizophrenia is not primarily a genetic disease because when you stop people who have schizophrenia from reproducing it has no effect on the subsequent incidence of the disease. For a full century, from the 1850s to the 1950s, 
we hospitalized most people with severe schizophrenia and did not allow them to reproduce. During that time in North America and Western Europe, the incidence of schizophrenia did not decrease but rather increased. In the United States between 1907 and 1940, more than 18,000 people with schizophrenia and bipolar disorder were sterilized, three quarters of them in the states of California, Kansas, and Virginia. However there is no evidence that the sterilizations had any effect on the future incidence of psychiatric disorders in those states or in the United States as a whole. The definitive test of the efficacy of eugenics for decreasing the incidence of schizophrenia was the horrific public policies of Nazi Germany. Between 1934 and 1945 , it was estimated that 132,000 people with schizophrenia were sterilized and approximately an equal number were killed. This totaled at least three quarters of all individuals with schizophrenia in Germany prior to World War II. Postwar studies reported a low prevalence rate for schizophrenia, as expected, but a relatively high incidence of the disease. Thus eliminating reproduction by individuals with schizophrenia had no effect on the future incidence of the disease [25].

So how might Toxoplasma gondii run in families and thus be a familial disease but not be a genetic disease? As noted in Chap. 2, toxoplasmosis often runs in families, for example, from shared food such as undercooked lamb or raw goat's milk. Family outbreaks have also occurred from sharing an oocyst-contaminated water source. Extended families also often socialize together, thus exposing family members to a common risk factor. For example, the preschool children of an extended family in Alabama often played together in a yard with a toxoplasmosis-positive cat which had recently given birth to kittens. Seven of the nine preschool children were diagnosed with symptomatic toxoplasmosis. The common denominator of the children who became ill was a habit of putting sand or dirt in their mouth. A familial pattern of toxoplasmosis is also produced occasionally when an infected woman gives birth to two children who are congenitally infected; this may occur over a period of many years. There is also an intriguing pattern of familial toxoplasmosis which has been documented in mice. Toxoplasma gondii can be passed from generation to generation in mice, just as a gene would be, for as many as ten generations. Whether this also happens in humans is not known [26-28].

\subsection{Why Isn't There More Psychosis?}

Given the fact that 40 million Americans are infected with Toxoplasma gondii and that we have an estimated 140 million cats, wouldn't we expect psychosis to be more common if this parasite really does cause some cases of psychosis? In fact, we do not have very good information on the true prevalence of psychosis in the United States. The last reliable survey of this question was carried out by the National Institutes of Mental Health (NIMH) in the early 1980s and reported that $1.1 \%$ of adults or approximately 2.8 million people had schizophrenia at that time. A recent study, based on Medicaid and Medicare data, reported that $1.6 \%$ of the adult population, or approximately 3.8 million people, now have the symptoms of schizophrenia. This study did not include mentally ill individuals in jails and prisons of which, one study suggests, there may be another 200,000 individuals with schizophrenia. 
Thus the total number of people with schizophrenia in the United States is probably about 4 million, and that number does not include individuals with psychosis associated with bipolar disorder or major depression. If T. gondii is responsible for causing even one quarter of these, that is a lot of psychosis [29].

Another consideration in regard to why there is not more psychosis is the fact that infectious diseases change over time. This is the theory of evolutionary epidemiology. According to this theory, "pathogen virulence and horizontal transmission is highest at the onset of an epidemic but decreases thereafter, as the epidemic depletes the pool of susceptible hosts." Thus the disease spreads most rapidly and is the most severe when it first becomes manifest. At some point in time, depending on the host characteristics and patterns of transmission, the incidence of the disease levels off. This has been demonstrated to occur in epidemics such as syphilis which was a much more severe disease when it was introduced in Europe in the early sixteenth century. Additional evidence that this is also true for schizophrenia is the fact that clinically it appears to have become a less severe disease in recent decades with fewer cases seen with catatonic or hebephrenic features and recovery occurring more frequently [30-32].

Returning to the original question, given the fact that there appears to be a correlation between the rise of cats and the rise of psychosis, is it likely that the correlation represents causation? By examining other aspects of psychosis, how well can they be explained by invoking $T$. gondii, a parasite carried by cats. In short, is the theory plausible? I believe the answer is yes, it is plausible.

\section{References}

1. Torrey EF, Miller J. The invisible plague: the rise and fall of mental illness from 1950 to the present. New Brunswick: Rutgers University Press, 343; 2002.

2. Chandrasekaran V. Correlation or causation? Bloomberg Businessweek, December 1, 2011.

3. Wallace GD. Serologic and epidemiologic observations on toxoplasmosis on three Pacific atolls. Am J Epidemiol. 1969;90(2):103-11. https://doi.org/10.1093/oxfordjournals.aje. a121054.

4. Torrey EF, et al. The epidemiology of schizophrenia in Papua New Guinea. Am J Psychiatry. 1974;131:567-73.

5. Nimgaonkar VL, et al. Low prevalence of psychoses among the Hutterites, an isolated religious community. Am J Psychiatry. 2000;157:1065-70. https://doi.org/10.1176/appi.ajp.157.7.

6. Torrey EF. Prevalence of psychosis among the Hutterites: a reanalysis of the 1950-53 study. Schizophr Res. 1995;16(2):167-70.

7. Saha S, et al. A systematic review of the prevalence of schizophrenia. PLoS Med. 2005;2(5):e141. https://doi.org/10.1371/journal.pmed.0020141.

8. Boyer K, et al. Unrecognized ingestion of Toxoplasma gondii oocysts leads to congenital toxoplasmosis and causes epidemics in North America. Clin Infect Dis Soc Am. 2011;53:1081-9.

9. Torrey EF, et al. Seasonality of births in schizophrenia and bipolar disorder: a review of the literature. Schizophr Res. 1997;28:1-38.

10. Lass A, et al. The first detection of Toxoplasma gondii DNA in environmental air samples using gelatine filters, real-time PCR and loop-mediated isothermal (LAMP) assays: qualitative and quantitative analysis. Parasitology. 2017;144(13):1791-801.

11. Teutsch SM, et al. Epidemic toxoplasmosis associated with infected cats. N Engl J Med. 1979;300(13):695-9.

12. Torrey EF, Yolken RH. The urban risk and migration risk factors for schizophrenia: are cats the answer? Schizophr Res. 2014;159:299-302. 
13. Jongsme HE, et al. Treated incidence of psychotic disorders in the multinational EU-GEI study. JAMA Psychiat. 2018;75:36-46.

14. White WA. The geographical distribution of insanity in the United States. J Nerv Ment Dis. 1903;30:257-79.

15. Gordon EB. Mentally ill West Indian immigrants. Br J Psychiatry. 1965;111:877-87.

16. Harrison G, et al. A prospective study of severe mental disorder in Afro-Caribbean patients. Psychol Med. 1988;18:643-57.

17. Hutchinson G, Haason C. Migration and schizophrenia. Soc Psychiatry Psychiatr Epidemiol. 2004;39:350-7.

18. Kirkbride JB, et al. Incidence of schizophrenia and other psychoses in England, 1950-2009: a systematic review and meta-analysis. PLoS One. 2012;7:e31660. https://doi.org/10.1371/ journal.pone.0031660.

19. Dubey JP, et al. Toxoplasmosis in the Caribbean Islands. Parasitol Res. 2016;115:1627-34.

20. Gilbert RE, et al. Prevalence of Toxoplasma IgG among pregnant women in West London according to country of birth and ethnic group. Br Med J. 1993;306:185-9.

21. Flatt A, Shetty N. Seroprevalence and risk factors for toxoplasmosis among antenatal women in London. Eur J Pub Health. 2012;23:648-52.

22. Moura L, et al. Seroprevalence of Toxoplasma gondii in cats from St. Kitts, West Indies. J Parasitol. 2007;93:952-3.

23. Leo J. The search for schizophrenia genes. Issues Sci Technol. 2016;32:68-72.

24. Corvin A, Morris DW. Genome-wide association studies: findings at the major histocompatibility complex locus in psychosis. Biol Psychiatry. 2014;75:276-83.

25. Torrey EF, Yolken RH. Psychiatric genocide: Nazi attempts to eradicate schizophrenia. Schizophr Bull. 2010;36:26-32.

26. Stagno S, et al. An outbreak of toxoplasmosis linked to cats. Pediatrics. 1980;65:706-12.

27. Beverley JKA. Congenital transmission of toxoplasmosis through successive generations of mice. Nature. 1959;183:1348-9.

28. Dubey JP. History of the discovery of the life cycle of Toxoplasma gondii. Int J Parasitol. 2009;39:877-82.

29. Mojtabai R. Estimating the prevalence of schizophrenia in the United States using the multiplier method. Lett Schizophr Res. 2021;240:48-9.

30. Berngruber TW, et al. Evolution of virulence in emerging epidemics. PLoS Pathog. 2013;9:e1003209.

31. Bolker BM, et al. Transient virulence of emerging pathogens. J R Soc Interface. 2010;7:811-22.

32. McGlashan TH. At issue: is natural selection rendering schizophrenia less severe? Schizophr Bull. 2006;32:428-9.

Open Access This chapter is licensed under the terms of the Creative Commons AttributionNonCommercial-NoDerivatives 4.0 International License (http://creativecommons.org/licenses/ by-nc-nd/4.0/), which permits any noncommercial use, sharing, distribution and reproduction in any medium or format, as long as you give appropriate credit to the original author(s) and the source, provide a link to the Creative Commons license and indicate if you modified the licensed material. You do not have permission under this license to share adapted material derived from this chapter or parts of it.

The images or other third party material in this chapter are included in the chapter's Creative Commons license, unless indicated otherwise in a credit line to the material. If material is not included in the chapter's Creative Commons license and your intended use is not permitted by statutory regulation or exceeds the permitted use, you will need to obtain permission directly from the copyright holder. 